\title{
Signs, Symptoms, Parafunctions and Associated Factors of Parent-Reported Sleep Bruxism in Children: A Case-Control Study
}

\author{
Júnia Maria SERRA-NEGRA ${ }^{1}$ \\ Saul Martins PAIVA ${ }^{1}$ \\ Sheyla Márcia AUAD ${ }^{1}$ \\ Maria Letícia RAMOS-JORGE ${ }^{2}$ \\ Isabela Almeida PORDEUS ${ }^{1}$ \\ ${ }^{1}$ Department of Pediatric Dentistry and Orthodontics, \\ UFMG - Universidade Federal de Minas Gerais, Belo Horizonte, MG, Brazil \\ ${ }^{2}$ Department of Pediatric Dentistry, UFVJM - Federal University of Vales do Jequitinhonha e Mucuri, \\ Diamantina, $M G$, Brazil
}

\begin{abstract}
Bruxism is the non-functional clenching or grinding of the teeth that may occur during sleep or less commonly in daytime. The aim of this study was to investigate the association between clinical signs and symptoms, parafunctions and associated factors of sleep bruxism in children. A population-based case-control study was carried out involving 120 children, 8 years of age, with sleep bruxism and 240 children without sleep bruxism. The sample was randomly selected from public and private schools in the city of Belo Horizonte, MG, Brazil. Groups were matched by gender and social class. The Social Vulnerability Index (SVI) drawn up by the city of Belo Horizonte was employed for social classification. Data collection instruments included clinical forms and pre-tested questionnaires. The diagnosis of sleep bruxism was supported by the American Association of Sleep Medicine (AASM) criteria. The McNemar test, binary and multivariate logistic regression models were used for statistical analysis. The risk factors associated with sleep bruxism included: primary canine wear (OR=2.3 IC 95\% 1.2-4.3), biting of objects like pencils or pens (OR=2.0 IC 95\% 1.2-3.3) and wake-time bruxism (tooth clenching) ( $\mathrm{OR}=2.3 \mathrm{IC} 95 \%$ 1.2-4.3). Children that present the parafunctions of object biting and wake-time bruxism were more susceptible to sleep bruxism.
\end{abstract}

Key Words: bruxism, children, epidemiology, parafunction, parasomnia.

\section{INTRODUCTION}

Bruxism is the non-functional clenching or grinding of the teeth that may occur during sleep or less commonly in daytime, and affects both children and adults (1-7). The consequences of bruxism include temporomandibular disorders, muscle pain, periodontal problems, dental wear and tooth loss (8-15). Its aetiology is still controversial but the multifactorial cause has mainly been attributed to pathophysiologic, psychologic and morphologic factors (4-13). Moreover, in younger children, bruxism may be a consequence of the masticatory neuromuscular system immaturity (13).

There are several theories that associate emotional factors to the triggering of bruxism (2-7). Children who take on bruxism as a mechanism to release tension tend to present a greater chance of continuing this behavior in adult life (4-6). A habit that begins in childhood and remains until adult life can cause serious damage to the stomatognathic system, consequently triggering periodontal problems, temporomandibular disorders and even tooth loss (9-13).

Some extra- and intra-oral signs are associated with bruxism, such as changes in the facial symmetry, lip incompetence, pain upon palpation of the masseter and temporal muscle regions, headaches, temporomandibular disorders (TMD), mouth breathing, buccal mucosa ridging, tongue indentation as well as presence of anterior crossbite, posterior crossbite and dental wear (10-20).

Considerable discrepancy can be found in the

Correspondence: Profa Dra. Júnia Maria Serra-Negra, Faculdade de Odontologia, Departamento de Odontopediatria e Ortodontia, UFMG, Avenida Antonio Carlos, 6627, 31270-901 Belo Horizonte, MG, Brasil. Tel: +55-31-3409-2433. Fax +55-31-3409-2472. email: juniaserranegra@hotmail.com 
literature regarding the prevalence of bruxism $(5,7)$. In the USA, a $38 \%$ prevalence was found when parents' reports were used to assess sleep bruxism habits among schoolchildren (7). A Canadian study showed that 15\% of the children in Montreal exhibited sleep bruxism and $12.4 \%$ exhibited wake-time bruxism (18). Another study, based on parents' reports in Brazil, indicated a 35.3\% prevalence of sleep bruxism in children (5).

The difference in results among studies on sleep bruxism in children demonstrates the need to encourage research on this subject. There is also a need to standardize methodological criteria and study designs in an attempt to better diagnose bruxism and the severity of the repercussions of this habit. Therefore, the present case-control study aimed: a) to determine the association among signs and symptoms of parentreported sleep bruxism in children and its association with other parafunctions of Brazilian schoolchildren and b) to compare these findings with those of children without this condition.

\section{MATERIAL AND METHODS}

UFMG's Ethics Committee approved the protocol for this research. Parental consent was sought for children's participation in this investigation. Subjects were free to withdraw from the study at any stage.

\section{Study Design}

The sample included 8-year-old Brazilian elementary schoolchildren living in Belo Horizonte, MG, Brazil. The city of Belo Horizonte is the capital of the state of Minas Gerais and is located in the southeastern region of Brazil, with 2,238,526 inhabitants, 182,891 of whom are school-aged children (www.pbh.gov.br).

This population-based case-control study was performed using a proportion of 1:2 and a two-stage stratified random-sampling method. The first stage included the randomization of 9 public and 9 private schools. The second stage included the randomization of the children within the list of students.

\section{Sample Size Calculation}

A $99 \%$ confidence interval level and a $35.0 \%$ prevalence of sleep bruxism were also used in the sample calculation. The case group consisted of 120 children with sleep bruxism as reported by parents, whereas the control group consisted of 240 children without sleep bruxism.

\section{Social Classification}

The Social Vulnerability Index (SVI) was employed for socioeconomic classification (21). This index measures the level of social exclusion in the city of Belo Horizonte, as it encompasses over 20 variables that quantify the population's access to housing, schooling, income, jobs, legal assistance, health and nutrition (21). As such, the SVI measures social access and determines to what extent the population of each region of the city is vulnerable to social exclusion. The SVI is divided into 5 categories (21). Class I represents regions with the greatest degree of vulnerability, while Class V represents those with the lowest degree of vulnerability. Along with gender and age, this social classification was used to match the groups with and without sleep bruxism. The city hall database concerning SVI scores was used to determine the residential SVI based on the address of each family. Schools were selected by lots, using the SVI of the different regions of the city. Correlation between the school's SVI and the student's residence was analyzed (Spearman's Correlation Coefficient $=$ 0.78). The child's SVI is always provided by the SVI of the child's residence. For statistical analysis, SVI was divided into two groups of social vulnerability: "high" (classes I and II) and "low" (classes III, IV and V).

\section{Case-Control Definition}

The sample of this case-control study was paired by gender and socioeconomic status. Since these variables were used to match the case and control groups, the sample consisted of $50 \%$ male and $50 \%$ female; $50 \%$ "low social vulnerability" and 50\% "high social vulnerability"; $50 \% 8$ year children with sleep bruxism and $50 \% 8$ year children without sleep bruxism.

\section{Data Collection Instruments}

Data collection instruments included a questionnaire for parents/caretakers and a clinical form.

Presence or absence of sleep bruxism was determined by parents' reports (4-7). Data were collected by a self-completed questionnaire that was sent to the parents attached to the students' homework. The questionnaire included 10 questions with information on the child's history of audible teeth grinding at night, 
oral habits, medical history and sociodemographic information (4-7,13-18). To ensure that sleeping arrangements were related to the reporting of sleep bruxism, the survey inquired as to the number of times a parent checks on a child during the night, proximity of the parents' and children's bedrooms, and whether the doors of the parents' and children's rooms remain open or closed $(5,7)$. The diagnosis of sleep bruxism was supported by the classification criteria of the American Academy of Sleep Medicine (AASM) (4-6). AASM criteria included: parents indicating the occurrence of audible teeth grinding at night; no other medical or mental disorders (e.g. sleep-related epilepsy, cases of abnormal movement while sleeping) and no other sleep disorders (e.g. obstructive sleep apnea syndrome) (5).

All parents were instructed to observe over a 3-day period and record in the questionnaire anything concerning the presence or absence of sleep bruxism among their children. The school sent the questionnaire along with the children's homework and a reminder for the parents to fill out the questionnaire within 3 days. Case and control groups were classified by the parents' reports according to the presence or absence of audible teeth grinding during the night $(6,7)$.

\section{Pilot Study}

Dental assessments were carried out by a single dentist who participated in a training and calibration exercise to become aware of the criteria used to identify each examined clinical condition. The theoretical step involved a discussion of the criteria established for the diagnosis of each oral health condition by the analysis of 55 photographs (Cohen's Kappa values minimum and maximum values of 0.72 and 0.89 ).

In the calibration process, 150 children were examined and 20 were re-examined after 1-month interval to calculate the intraexaminer agreement. The children in the pilot study were not included in the main sample. The results of the pilot study revealed that there was no need to change the previously proposed methods. Hence, the quality of collected data was assured.

Cohen's Kappa values were obtained by collecting data from a single examiner presenting minimum and maximum values of 0.80 and 0.90 , respectively.

\section{Data Collection}

During the examination, the examiner sat in front of the child, who remained standing. A head lamp (Peltz; Tikka XP, Crolles, France) and disposable mouth mirror (Prisma, São Paulo, SP, Brazil) were used for the dental examination. Examinations were conducted at school during daytime class hours. Before the dental examination, the children were asked to brush their teeth, which were dried with sterilized cotton rolls.

Sleep bruxism signs and symptoms were evaluated in a clinical examination. The investigated signs and symptoms included: facial asymmetry, lip incompetence, pain in the masseter and temporal muscle regions, TMD, buccal mucosa ridging, tongue indentation, anterior crossbite, posterior crossbite, mouth breathing and primary dental wear $(8-20,22-25)$.

\section{Clinical Examination Criteria}

To evaluate the presence of facial symmetry, the examiner considered an imaginary vertical line, dividing the child's face from the root of the child's hair to the chin, considering it as normal when harmony between the left and right sides could be observed (20). Children were considered to be lip incompetent when they were unable to keep their lips pressed together, or when they contracted the orbicular muscle, employing a facial mimicking in the chin region $(16,17,20)$.

To evaluate the presence of muscular pain, the researcher pinched the region from the masseter muscle to the temporal muscle between her fingers and asked the child if he/she felt any pain during this action (8). Upon finishing this muscle evaluation, the temporomandibular joint region was evaluated (11). The presence of clicks or deviations when opening or closing the mouth indicated TMD (11-15).

The cheek mucosa along the occlusal line, as well as along the lateral borders of the tongue, were assessed to determine the presence of buccal mucosa ridging and tongue indentation $(14,15)$. During the examination, one factor was determinant to analyze mouth breathing: fogging on the lower portion of a double-faced mirror (16).

The presence of anterior and posterior crossbites was also evaluated, since for some authors, malocclusion can lead to sleep bruxism $(1,20,24)$. Posterior crossbite is also known as "reverse articulation" and anterior crossbite cannot be referred as negative overjet and is typical of class III skeletal relations (24). In crossbite, an inversion occurs at the interface of cusp-to-fossa with a greater risk of premature dental contact which 
could destabilize the mandible, favoring sleep bruxism in turn (24). Evaluations of occlusion were performed by positioning the dental arches in a centric relation (1).

During clinical examination, a distinction was made between the processes of attrition and dental erosion, since dental erosion occurs as a result of a chemical process $(22,23)$. The clinical features of dental erosion include the loss of surface characteristics, a melted appearance, the presence of cupping on occlusal and grooving on incisal surfaces and shallow concavities $(22,23)$. Loss of dental substance due to attrition often presents antagonistic plane facets with sharp margins $(22,23)$. Teeth with carious lesions and extensive restorations were excluded from the examination.

Children enrolled in the study were in the mixed dentition phase. Thus, only primary dental wear was evaluated, taking into consideration that the permanent teeth had erupted very recently and did not have sufficient time to be exposed to wear for a reliable analysis (20). For analysis in the present study, the dichotomization of dental wear was adopted and divided into two categories: a first group with wear, with no concern as to its intensity, and a second group without wear.

During the clinical examination, the children were also asked if they had any headaches and if the answer was "yes", they were asked to use their hands to show the exact location where this pain had occurred (19). According to the location shown by the child, complaints could be observed in the following regions: temporal, frontal, occipital and top of the head.

\section{Statistical Analysis}

Statistical analysis was performed using the Software Package for Social Sciences (SPSS for Windows, version 17.0; SPSS Inc, Chicago, IL, USA). The present study analyzed the dependent variable concerning the presence or absence of sleep bruxism and the independent variable concerning the signs and symptoms evaluated during the clinical examination and parafunctions. McNemar test, binary and multivariate logistic regression, was applied for statistical analysis, with $p<0.05$ set as the confidence interval.

\section{RESULTS}

A statistically significant association between most studied variables and sleep bruxism could be observed. Facial symmetry was present in $79.2 \%$ of the case group and $82.5 \%$ of the lip incompetence group (Table 1). Only three children with sleep bruxism (2.5\%) presented TMD, while $4(1.7 \%)$ presented no sleep bruxism. Headaches were reported by $65.9 \%$ of the children.

The oral clinical variables that presented an association with sleep bruxism included: primary canine wear $(81.7 \%)(p<0.001)$, clenching teeth when awake $(70.6 \%)(p<0.001)$, mouth breathing $(60.2 \%)(p=0,002)$, object biting like pencils or pens $(59.2 \%)(\mathrm{p}=0.001)$ and nail biting (50.8\%) $(\mathrm{p}=0.001)$ (Table 2$)$.

Only 4 children with sleep bruxism (3.4\%) presented an anterior crossbite, whereas $16.8 \%$ presented a posterior crossbite $(\mathrm{p}<0.001)$ (Table 2$)$.

To evaluate the probability of sleep bruxism occurrence, a logistic model was created with explicative variables that present a significant association. Next, using this model, the statistically significant independent variables were selected. To select the variables from the logistic model, a stepwise procedure, considering the inclusion of all significant variables, was performed. Each variable was analyzed step by step and those in which no significance could be observed were excluded.

The risk factors associated with sleep bruxism included: primary canine wear $(\mathrm{OR}=2.3$ IC 1.2 $4.3)$, object biting ( $\mathrm{OR}=2.0$ IC 1.2-3.3) and teeth clenching when awake (OR=2.3 IC 1.2-4.3) (Table 3 ). Mouth breathing presented no association in the logistic regression model; however, the limit value did demonstrate a tendency that needs further investigation $(\mathrm{p}=0.054)($ Table 3$)$.

\section{DISCUSSION}

The aim of the present study was to determine the association among signs, symptoms and other associated factors reported by parents concerning sleep bruxism in children.

The first factor to be analyzed was the dental wear, which is an important sign in the detection of sleep bruxism $(18,20)$. Canine wear leads to the analysis that these teeth are located in the dental arch, in the transition area between the anterior and posterior teeth and have an important function as occlusion guides, and are thus subjected to great efforts on its structure (20).

Anterior crossbites, buccal mucosa ridging and tongue indentation formulated a behavior that was the exact opposite of what was expected, as the presence of these clinical signs frequently indicates sleep bruxism. 
$(13-15,24)$. However, these signs appeared more often in children without sleep bruxism $(9,13)$. Other authors, however, emphasized that, in addition to the low number of children who in fact present these changes in the case group, these signs may well be associated with other parafunctions, which may have acted as a confusion

Table 1. Descriptions of percentages by analysis of association between extra-oral clinical variables and sleep bruxism in children.

\begin{tabular}{|c|c|c|c|}
\hline \multirow{2}{*}{$\begin{array}{l}\text { Extra-oral clinical } \\
\text { variables }\end{array}$} & \multicolumn{2}{|c|}{ Sleep bruxism } & \multirow{2}{*}{$\begin{array}{c}\mathrm{p} \\
\text { value* }\end{array}$} \\
\hline & Case & Control & \\
\hline \multicolumn{4}{|l|}{ Facial symmetry } \\
\hline No & $25(20.8)$ & $61(25.4)$ & \multirow{2}{*}{$<0.001$} \\
\hline Yes & $95(79.2)$ & $179(74.6)$ & \\
\hline \multicolumn{4}{|l|}{ Lip incompetence } \\
\hline No & $21(17.5)$ & $46(19.2)$ & \multirow{2}{*}{$<0.001$} \\
\hline Yes & $99(82.5)$ & 194(80.8) & \\
\hline \multicolumn{4}{|c|}{ Masseter muscle pain } \\
\hline No & $91(75.8)$ & $187(77.9)$ & \multirow{2}{*}{0.002} \\
\hline Yes & $29(24.2)$ & $53(22.1)$ & \\
\hline \multicolumn{4}{|c|}{ Temporal muscle pain } \\
\hline No & $88(73.3)$ & $182(75.8)$ & \multirow{2}{*}{0.016} \\
\hline Yes & $32(26.7)$ & $58(24.2)$ & \\
\hline \multicolumn{4}{|l|}{ Temporomandibular } \\
\hline No & $03(2.5)$ & $04(1.7)$ & \multirow[t]{2}{*}{$<0.001$} \\
\hline \multicolumn{3}{|l|}{ Yes } & \\
\hline \multicolumn{4}{|l|}{ Headaches } \\
\hline No & $41(34.1)$ & $91(37.9)$ & \multirow{2}{*}{$<0.001$} \\
\hline Yes & $79(65.9)$ & $149(62.1)$ & \\
\hline \multicolumn{4}{|l|}{$\begin{array}{l}\text { Headaches temporal } \\
\text { muscle }\end{array}$} \\
\hline No & $83(69.2)$ & $168(70.0)$ & \multirow{2}{*}{0.422} \\
\hline Yes & $37(30.8)$ & $72(30.0)$ & \\
\hline \multicolumn{4}{|l|}{ Headaches frontal } \\
\hline No & $37(30.8)$ & $74(30.8)$ & \multirow[t]{2}{*}{0.523} \\
\hline \multicolumn{3}{|l|}{ Yes } & \\
\hline \multicolumn{4}{|l|}{ Headaches occipital } \\
\hline No & $07(5.8)$ & $11(4.6)$ & \multirow[t]{2}{*}{$<0.001$} \\
\hline Yes & & & \\
\hline \multicolumn{4}{|c|}{ Headaches on top part } \\
\hline of head & $115(95.8)$ & $235(97.9)$ & \multirow{2}{*}{$<0.001$} \\
\hline $\begin{array}{l}\text { No } \\
\text { Yes }\end{array}$ & $05(4.2)$ & $05(2.1)$ & \\
\hline
\end{tabular}

* Mc Nemar test - values in parentheses refer to the percentages between columns. factor in the analysis $(13,24)$. In the present study, the posterior crossbite proved to be not associated with sleep bruxism, which agrees with the results of Miamoto et al. (24). This item was excluded when analyzing the adjusted logistic regression model (Table 3 ).

The methodology of clinical observation of dental

Table 2. Descriptions of percentages by the analysis of association between oral clinical variables and sleep bruxism in children.

\begin{tabular}{|c|c|c|c|}
\hline \multirow{2}{*}{$\begin{array}{l}\text { Oral clinical } \\
\text { variables }\end{array}$} & \multicolumn{2}{|c|}{ Sleep bruxism } & \multirow{2}{*}{$\begin{array}{c}\mathrm{p} \\
\text { value* }\end{array}$} \\
\hline & Case & Control & \\
\hline \multicolumn{4}{|c|}{ Buccal mucosa ridging } \\
\hline No & $27(22.5)$ & $51(21.3)$ & \multirow{2}{*}{$<0.001$} \\
\hline Yes & $93(77.5)$ & $189(78.8)$ & \\
\hline \multicolumn{4}{|c|}{ Tongue indentation } \\
\hline No & $110(91.7)$ & $216(90.0)$ & \multirow{2}{*}{$<0.001$} \\
\hline Yes & $10(8.3)$ & $24(10.0)$ & \\
\hline \multicolumn{4}{|c|}{ Anterior crossbite } \\
\hline No & $115(96.6)$ & $224(93.3)$ & \multirow{2}{*}{$<0.001$} \\
\hline Yes & $04(3.4)$ & $16(6.7)$ & \\
\hline \multicolumn{4}{|c|}{ Posterior crossbite. } \\
\hline No & $99(83.2)$ & $186(77.5)$ & \multirow{2}{*}{$<0.001$} \\
\hline Yes & $20(16.8)$ & $54(22.5)$ & \\
\hline \multicolumn{4}{|c|}{ Primary canine wear } \\
\hline No & $22(18.3)$ & 79 (32.9) & \multirow{2}{*}{$<0.001$} \\
\hline Yes & $98(81.7)$ & $161(67.1)$ & \\
\hline \multicolumn{4}{|c|}{ Primary first molar wear } \\
\hline No & $52(43.3)$ & $131(54.6)$ & \multirow{2}{*}{0.001} \\
\hline Yes & $68(56.7)$ & $109(45.4)$ & \\
\hline \multicolumn{4}{|c|}{$\begin{array}{l}\text { Primary second molar } \\
\text { wear }\end{array}$} \\
\hline wear & $92(76.7)$ & $188(78.3)$ & \multirow{2}{*}{0.001} \\
\hline Yes & $28(23.3)$ & $52(21.7)$ & \\
\hline \multicolumn{4}{|l|}{ Nail biting } \\
\hline No & $59(49.2)$ & $136(56.7)$ & \multirow{2}{*}{0.001} \\
\hline Yes & $61(50.8)$ & $104(43.3)$ & \\
\hline \multicolumn{4}{|c|}{ Biting of objects } \\
\hline No & $49(40.8)$ & $150(62.8)$ & \multirow{2}{*}{0.001} \\
\hline Yes & $71(59.2)$ & $89(37.2)$ & \\
\hline \multicolumn{4}{|c|}{$\begin{array}{l}\text { Clenching teeth when } \\
\text { awake }\end{array}$} \\
\hline awake & $35(29.4)$ & $211(87.9)$ & \multirow{2}{*}{$<0.001$} \\
\hline $\begin{array}{l}\text { No } \\
\text { Yes }\end{array}$ & $84(70.6)$ & $29(12.1)$ & \\
\hline \multicolumn{4}{|c|}{ Mouth breathing } \\
\hline No & $48(39.8)$ & $260(72.2)$ & \multirow{2}{*}{0.002} \\
\hline Yes & $72(60.2)$ & $100(27.8)$ & \\
\hline
\end{tabular}

*Mc Nemar test - values in parentheses refer to the percentages between columns. 
wear may be a limitation of this study. In addition, varied prevalence rates may also result from the diversity of collection instruments used to assess the habit of bruxism among children (25), or even those based on self-reports/ parents' reports $(4-7,18)$. However, one observation seems to be consistent in the majority of studies: the multifactorial aetiology of sleep bruxism (1-9).

The evaluation of dental wear in children with mixed dentitions may also have been a limitation of this study. During the act of grinding the teeth, the anterior teeth commonly receive a greater load, and thus become more susceptible to wear (20). Verifying the dental wear in primary dentitions in slightly younger children would be one way of evaluating possible wear in deciduous teeth in the anterior region. Nevertheless, it is in the mixed dentition phase that the majority of mandibular instabilities occur, mainly due to the substitution of teeth, which predisposes the child to sleep bruxism (20). For this reason, the present study opted to work with children within this specific age range.

Kappa coefficients provided a consistent basis to the criteria used in the clinical examination, with values varying from 0.80 to 0.90 , which demonstrate an excellent agreement and support the applied methodology.

Basing a study on parents' reports in an attempt to determine the presence or absence of sleep bruxism among children has been employed in other studies, and is described by the AASM as a key element in detecting the presence of sleep bruxism (4-7). This methodology was also approved by Cheifetz et al. (7). As sleep

Table 3. Description of multivariate logistic regression between signs, symptoms and associated factors of sleep bruxism among children.

\begin{tabular}{lcccc}
\hline Variable & $\begin{array}{c}\text { Unadjusted } \\
\text { OR } \\
(95 \% \mathrm{CI})\end{array}$ & $\mathrm{p}$ value & $\begin{array}{c}\text { Adjusted OR } \\
(95 \% \mathrm{CI})\end{array}$ & $\begin{array}{c}\mathrm{p} \\
\text { value }\end{array}$ \\
\hline $\begin{array}{l}\text { Primary canine wear } \\
\quad \text { No }\end{array}$ & 1 & & 1 & \\
$\quad$ Yes & $2.1(1.2-3.7)$ & 0.004 & $2.3(1.2-4.3)$ & 0.005 \\
$\begin{array}{l}\text { Biting on objects } \\
\text { No }\end{array}$ & 1 & & & \\
$\quad$ Yes & $2.4(1.5-3.8)$ & 0.000 & $2.0(1.2-3.3)$ & 0.004 \\
$\begin{array}{l}\text { Clenching teeth } \\
\text { No }\end{array}$ & & & & \\
$\quad$ Yes & 1 & & 1 & \\
Mouth breathing & $3.0(1.7-5.2)$ & 0.000 & $2.3(1.2-4.3)$ & 0.004 \\
$\quad$ No & & & & \\
$\quad$ Yes & 1 & & 1 & \\
\hline
\end{tabular}

bruxism is characterized by the noise, it is believed that the parents had no difficulties in observing sleep bruxism in their children (4-7). The same cannot be said of children who suffer from the wake-time bruxism (tooth clenching). This habit does not create noise. Some parents based their observations on the facial expressions of their children to report its presence. Those children who intensely contract the masseter muscle and demonstrate this behavior with an expression of anger and irritability are easily recognized $(8,18)$. Contractions that do not involve facial expressions were most likely not reported. Nonetheless, this was an important piece of information which detected a marked expression in the parafunction studied. The difficulty in dealing with anger is a personality trait that may well be associated with sleep bruxism, as reported elsewhere (4).

In the logistic model, it could be observed that children who present the parafunctions of object biting (pencils or pens) and wake-time bruxism (tooth clenching) are susceptible to sleep bruxism. Habits involving the act of biting may well be related to the expression of an individual when releasing tension and aggressiveness in an alert state (8). Previous studies have also shown an association between emotional factors and bruxism $(2,4-7)$.

This epidemiological study chose to apply a case-control design at a 1:2 proportion, pairing the groups by gender and social status, which provided a homogenous sample, a strong point in the methodology applied in this study.

The logistic model points out an association with other parafunctions, which reinforces the complexity of this oral condition and the fact of being a parafunction with a multifactorial aetiology (13).

The presence of dental wear, object biting and wake-time bruxism (tooth clenching) are important aspects to analyze within a clinical questionnaire in the dental practices. Therefore, monitoring children and their families through longitudinal studies is important to provide basis for a better understanding of sleep bruxism.

Based on the obtained results, it may be concluded that there is an association between sleep bruxism and other parafunctions in children. Children who present the parafunctions of biting on objects, such a pencils and pens, and wake-time bruxism were more 
susceptible to developing sleep bruxism.

\section{ACKNOWLEDGEMENTS}

This study was supported by the following Brazilian funding agencies: National Council for Scientific and Technological Development (CNPq) and the State of Minas Gerais Research Foundation (FAPEMIG).

\section{RESUMO}

Bruxismo é o ato não funcional de ranger os dentes enquanto se dorme ou apertar os dentes em vigília. O objetivo deste estudo foi investigar a associação entre sinais e sintomas clínicos associados ao bruxismo noturno em crianças. Foi desenvolvido um estudo de base populacional com desenho caso-controle, envolvendo 120 crianças, de 8 anos de idade, com bruxismo e 240 crianças sem bruxismo. A amostra foi selecionada de forma randomizada em escolas públicas e particulares da cidade de Belo Horizonte, Brasil. Os grupos caso e controle foram pareados por gênero e classe social. O Índice de Vulnerabilidade Social (IVS) desenvolvido pela prefeitura da cidade de Belo Horizonte foi utilizado para a classificação social. Como instrumentos de coleta foram utilizados: uma ficha clínica e um questionário pré-testados. O diagnóstico de bruxismo noturno foi baseado nos critérios da American Association of Sleep Medicine (AASM). Os testes estatísticos de McNemar, regressão logística binária e multivariada com modelo de regressão foram utilizados para análise dos dados. Foram considerados fatores de risco para o bruxismo noturno: desgaste em caninos decíduos (OR=2,3 IC 95\% 1,2-4,3), morder objetos como lápis e canetas ( $\mathrm{OR}=2,0 \mathrm{IC} 95 \%$ $1,2-3,3)$ e apertar os dentes em vigília (OR=2,3 IC 95\% 1,2-4,3). Crianças que apresentam outras parafunções tais como: morder objetos e apertar os dentes em vigília são mais susceptíveis ao bruxismo noturno.

\section{REFERENCES}

1. Valera FC, Travitzki LV, Mattar SE, Matsumoto MA, Elias AM, Anselmo-Lima WT. Muscular functional and orthodontic changes in preschool children with enlarged adenoids and tonsils. Int $\mathrm{J}$ Paediatr Otorhinolaryngol 2003;67:761-770.

2. Ferreira-Bacci AV, Cardoso CLC, Diaz-Serrano KV. Behavioral problems and emotional stress in children with bruxism. Braz Dent J 2012;23:246-251.

3. Herrera M, Valencia I, Grant M, Metroka D, Chialastri A, Kothare SV. Bruxism in children: effect on sleep architecture and daytime cognitive performance and behaviour. Sleep 2006;29:1143-1148.

4. Serra-Negra JM, Ramos-Jorge ML, Flores-Mendoza CE, Paiva SM, Pordeus IA. Influence of psychosocial factors on the development of sleep bruxism among children. Int J Paediatr Dent 2009; 19:309-317.

5. Serra-Negra JM, Paiva SM, Seabra AP, Dorella C, Lemos BF, Pordeus IA. Prevalence of sleep bruxism in a group of Brazilian schoolchildren. Eur Arch Paediatr Dent 2010;11:192-195.

6. Serra-Negra JM, Paiva SM, Flores-Mendoza CE, Ramos-Jorge ML, Pordeus IA. Association among stress, personality traits, and sleep bruxism in children. Pediatr Dent 2012;34:30-34.

7. Cheifetz AT, Osganian SK, Alfred EM, Needleman HL. Prevalence of bruxism and associated correlates in children as reported by parents. J Dent Child 2005;72:67-73.

8. Mason RM. A retrospective and prospective view of orofacial myology. Int J Orofacial Myology 2005;31:5-14.

9. Winocur E, Littner D, Adams I, Gavish A. Oral habits and their association with signs and symptoms of temporomandibular disorders in adolescents: a gender comparison. Oral Surg Oral Med Oral Pathol Oral Radiol Endod 2006;102:482-487.

10. Miyawaki S, Tanimoto Y, Araki Y, Katayama A, Imai M, TakanoYamamoto. Relationships among nocturnal jaw muscle activities, decreased esophageal $\mathrm{pH}$, and sleep positions. Am J Orthodont Dentofacial Orthop 2004;126:615-619.

11. Le Bell Y, Niemi PM, Jamsa T, Kylmala M, Alanen P. Subjective reactions to intervention with artificial interferences in subjects with and without a history of temporomandibular disorders. Acta Odontol Scand 2006;64:59-63.

12. Pergamalian A, Rudy TE, Zaki HS, Greco CM. The association between wear facets, bruxism, and severity of facial pain in patients with temporomandibular disorders. J Prosthet Dent 2003;90:194200.

13. Carlsson GE, Egermark I, Magnusson T. Predictors of bruxism, other oral parafunctions and dental wear over a 20 -year follow-up period. J Orofac Pain 2003;17:50-57.

14. Piquero K, Ando T, Sakurai K. Buccal mucosa ridging and tongue indentation: incidence and associated factors. Bull Tokyo Dent Coll 1999;40:71-78.

15. Takagi I, Sakurai K. Investigation of the factors related to the formation of the buccal mucosa ridging. J Oral Rehabil 2003;30:565-572.

16. Grechi TH, Trawitzki LV, de Felício CM, Valera FC, AnselmoLima WT. Bruxism in children with nasal obstruction. Int J Pediatr Otorhinolaryngol 2008;72:391-396.

17. Góis EG, Ribeiro-Júnior HC, Vale MP, Paiva SM, Serra-Negra JM, Ramos-Jorge ML, et al.. Influence of nonnutritive sucking habits, breathing pattern and adenoid size on the development of malocclusion. Angle Orthod 2008;78:647-654.

18. Carra MC, Huynh N, Morton P, Rompré PH, Papadakis A, Remise $\mathrm{C}$, et al.. Prevalence and risk factors of sleep bruxism and waketime tooth clenching in a 7-17-yr-old population. Eur J Oral Sci 2011;119:386-394

19. Biondi DM. Headaches and their relationship to sleep. Dent Clin North Am 2001;45:685-700.

20. Silness J, Johannessen G, Roynstrand T. Longitudinal relationship between incisal occlusion and incisal dental wear. Acta Odontol Scand 1993;51:15-21.

21. Braga L de S, Macinko J, Proietti FA, Cesar CC, Lima-Costa MF. Intra-urban differences in vulnerability among population. Cad Saúde Pública 2010;26:2307-2315.

22. Auad SM, Waterhouse PJ, Nunn JH, Moynihan PJ. Dental caries and its association with sociodemographics, erosion, and diet in schoolchildren from southeast Brazil. Pediatric Dent 2009;31:229235.

23. Ganss C. Definition of erosion and links to dental wear. Monog Oral Sci 2006;20:9-16.

24. Miamoto CB, Pereira LJ, Ramos-Jorge ML, Marques LS. Prevalence and predictive factors of sleep bruxism in children with and without cognitive impairment. Bras Oral Res 2011;25:439-445.

25. Restrepo C, Peláez A, Alvarez E, Paucar C, Abad P. Digital imaging of patterns of dental wear to diagnose bruxism in children. Int $\mathrm{J}$ Paediatr Dent 2006;16:278-285.

Received November 4, 2012 Accepted December 4, 2012 